\title{
An Assay Method for Screening Inhibitors of Prolyl 4-hydroxylase in Immortalized Rat Hepatic Stellate HSC-T6 Cells
}

\author{
Hwa Jung CHOI and Yunjo SoH* \\ Department of Dental Pharmacology, School of Dentistry, Chonbuk National University, Jeon-Ju, 561-756, Korea
}

(Received August 28, 2007; Accepted October 15, 2007)

\begin{abstract}
Hydroxyproline (HYP) is a post-translational product of proline hydroxylation catalyzed by an enzyme prolyl 4-hydroxylase $(\mathrm{P} 4 \mathrm{H})$ which plays a crucial role in the synthesis of all collagens. Considering the role of collagen and its significance in many clinically important diseases such as liver fibrosis, a great deal of attention has been directed toward the development of an assay at cell-based system. The reason is that cell-based assay system is more efficient than enzyme-based in vitro system and takes much less time than in vivo system. Several assay procedures developed for $\mathrm{P} 4 \mathrm{H}$ are laborious, time-consuming and not feasible for the massivescreening. Here, we report the cell-based assay method of prolyl 4-hydroxylase in immortalized rat hepatic stellate HSC-T6 cells. To optimize the cell culture condition to assay for HYP content, various concentrations of reagents were treated for different times in HSC-T6 cells. Our data showed that the treatment with ascorbate in a hypoxic condition for $24 \mathrm{~h}$ resulted in the maximal increase of HYP by 1.8 fold. Alternatively, cobalt chloride ( 5 $\mu \mathrm{M})$ and ascorbate $(50 \mu \mathrm{M})$ in normoxic states exhibited similar effect on the production of HYP as in a hypoxic condition. Therefore, cobalt chloride can be substituted for a hypoxic condition when an anaerobic chamber is not available. Rosiglitazone and HOE077, known as inhibitors of collagen, synthesis decreased P4H enzyme activity by $32.3 \%$ and $15 \%$, respectively, which coincided with previous reports from liver tissues. The level of the smooth muscle $\alpha$-actin, a marker of activated stellate cells, was significantly increased under hypoxia, suggesting that our experimental condition could work for screening the anti-fibrotic compounds. The assay procedure took only 3 days after treatment with agents, while assays from the primary stellate cells or liver tissues have taken several weeks. Considering the time and expenses, this assay method could be useful to screen the compounds for the inhibitor of prolyl 4-hydroxylase.
\end{abstract}

Keywords $\square$ Prolyl 4-hydroxylase, HSC-T6, Fibrosis, Hydroxyproline

\section{INTRODUCTION}

Prolyl 4-hydroxylase catalyzes the formation of 4-hydroxyproline (HYP) in collagens and more than 15 additional proteins with collagen like sequences (Hirsila et al., 2003). Liver fibrosis arises from the overproduction of extracellular matrix such as collagen resulting from chronic inflammation precipitated by viruses, alcohol, and other causes. Progressive fibrosis induces changes in the lobular architecture of the liver that lead to cirrhosis.

Even though primary stellate cell cultures are a useful tool for studying hepatic metabolism, their isolation is extremely time-consuming with modest yields and there is considerable

*Corresponding author

Tel: +82-63-270-4038, Fax: +82-63-270-4037

E-mail: ysoh@chonbuk.ac.kr variability in preparations. To overcome these limitations, we used an immortalized hepatic rat stellate cell line (HSC-T6 cells) which was generated by transfection of an expression plasmid encoding the SV40 large T antigen to primary stellate cells (Kim et al., 1998). HSC-T6 cells express myogenic and crest cytoskeletal filaments, like activated primary stellate cells.

Synthesis of collagen, the major component of the extracellular matrix, begins with the translation of collagen mRNA and hydroxylation of its proline moiety to hydroxyproline by prolyl 4-hydroxylase (Bickel et al., 1998). After several modifications, procollagen with a triple helix is formed, and is transported to the Golgi complex for secretion extracelluarly in secretory granules. Proline hydroxylation is thought to stabilize the triple helix of the collagen molecule, and since unhydroxylated procollagen shows a much slower rate of secretion, prolyl 4-hydroxylase is thought to be a key enzyme in the regulation of collagen synthesis. Thus, the inhibitor of prolyl 4-hydroxy- 
lase could be useful to prevent or treat fibrosis.

Hydroxyproline (HYP) in various tissues, plasma, and urine for the investigation of normal and pathological conditions of collagen metabolism is measured by colorimetric method (Kolar, 1990), HPLC (Langrock et al., 2007), GC/MS (Tredget et al., 1990) and enzymatic methods (Ono et al., 1999). The numerous assay procedures described before indicate the limits of each one with regarding to specificity, sensitivity, reproducibility, accuracy, and practical approach. However, the method described herein, which is a modification of an assay reported by Jamall et al., (1981) can determine HYP in nanogram levels and is applicable for practical approach without expensive instruments. In general, most of assay procedures described for HYP from biological tissues or primary stellate cells are laborious, time-consuming and not feasible for the massive-screening. To overcome these limitations, cell-based assay of prolyl 4-hydroxylase using HSC-T6 cells was introduced which took only 3 days after compounds treatment. With this assay method, compounds for the inhibitor of prolyl 4-hydroxylase could be effectively screened.

\section{MATERIALS AND METHODS}

\section{Materials}

Cell culture medium, fetal bovine serum (FBS) and horse serum were obtained from Invitrogen (Gaithersburg, MD, USA). All of the other chemicals were purchased from Sigma (St. Louis, MO, USA), unless otherwise indicated.

\section{4-Hydroxyproline (HYP) stock}

An HYP stock solution of $1 \mathrm{mg} / \mathrm{ml}$ was prepared in 50\% isopropanol. Solutions were freshly prepared by appropriate dilutions with $50 \%$ isopropanol.

\section{Other Reagents}

The 60\% Ehrlich's reagent solution, 20\% Chloramine-T solution, and Acetate-citrate buffer ( $\mathrm{pH}$ 6.5) were prepared as described else where (Jamall et al., 1981).

\section{Assay Procedure \\ Cell culture}

Rat hepatic stellate HSC-T6 cells (kindly provided by Dr. S. Friedman) were grown in DMEM supplemented with $10 \%$ FBS, penicillin $(100 \mathrm{U} / \mathrm{ml})$ and streptomycin $(100 \mu \mathrm{g} / \mathrm{ml})$ at 37 ${ }^{\circ} \mathrm{C}$ in a humidified atmosphere of $5 \% \mathrm{CO}_{2}$ (Vogel et al., 2000). Various concentrations of ascorbate were added to the DMEM
$2 \mathrm{~h}$ prior to treatment with agents and grown at an anaerobic chamber for $12 \mathrm{~h}, 24 \mathrm{~h}$ and $48 \mathrm{~h}$, respectively. Alternatively, cells were grown in the media containing $50 \mu \mathrm{M}$ ascorbate and $5 \mathrm{mM}$ lactate. Cobalt chloride was treated to the media instead of incubating cells under anaerobic conditions.

\section{Assay for 4-hydroxyproline in cell lysates}

Detection of HYP from HSC-T6 was performed by procedure from Jamall et al., (1981). Aliquots of the HSC-T6 cell lysates in triplicate were added to an equal volume of $12 \mathrm{~N} \mathrm{HCl}$ and hydrolyzed in Teflon-capped vials at $105^{\circ} \mathrm{C}$ for $18 \mathrm{~h}$. An aliquot of $200-\mu \mathrm{l}$ of $0.56 \%$ buffered chloramine-T was added to each vial. After a $10 \mathrm{~min}$ interval, $1.0 \mathrm{ml}$ of Ehrlich's reagent was added to give a final volume of $2.4 \mathrm{ml}$. All samples were mixed and then incubated at $50^{\circ} \mathrm{C}$ for $90 \mathrm{~min}$. The absorbances were read at $558 \mathrm{~nm}$ using water as reference and corrected for the reagent blank.

\section{Immunoblot analysis}

HSC-T6 cells were harvested and homogenized in a lysis buffer containing $20 \mathrm{mM}$ Tris- $\mathrm{HCl}, \mathrm{pH} 7.5,137 \mathrm{mM} \mathrm{NaCl}$, $10 \%$ glycerol, $1 \%$ Trixon $\mathrm{X}-100,1 \mathrm{mM} \mathrm{Na} \mathrm{VO}_{4}$, and $1 \mathrm{mM}$ PMSF. After centrifugation at $9,000 \times \mathrm{g}$ for $30 \mathrm{~min}$, supernatants were used as cytosolic extracts. Protein concentration was measured by Bradford method. Equal amounts of proteins were separated on $10 \%$ SDS-PAGE and then transferred to a polyvinylidene difluoride (PVDF) membrane (Bio-Rad). Membranes were blocked with 5\% nonfat skim milk in Tris-buffered saline (TBS) containing $0.5 \%$ Tween-20 (TTBS) at room temperature for $1 \mathrm{~h}$ and then incubated for $16 \mathrm{~h}$ at $4^{\circ} \mathrm{C}$ with rabbit anti- $\alpha$ SMA (1:250, NeoMarkers, Fremont, CA, USA), antibody diluted in 5\% nonfat milk in TTBS. Horseradish peroxidaseconjugated anti-rabbit antibody (Santa Cruz Biotechnology, Santa Cruz, CA, USA) was used as a secondary antibody (1: $5,000-1: 10,000$ dilution in 5\% nonfat skim milk in TTBS, for $1 \mathrm{~h}$ incubation at room temperature) and the antigen-antibody complexes were visualized by using an ECL Plus kit (Amersham Biosciences, Piscataway, NJ, USA). Western blot experiments were repeated at least three times with different cell preparations.

\section{Statistical analysis}

All the experimental data shown are expressed as the mean \pm S.D. and were repeated at least three times, unless otherwise indicated. Statistical analysis was performed with one-way analysis of variance (ANOVA) followed by a Student's t-test, 
and $p$-values less than 0.05 were considered significant.

\section{RESULTS AND DISCUSSION}

The measurement of hydroxyproline from cell lysates comprises three steps: 1) hydrolysis of protein by $\mathrm{HCl}, 2$ ) oxidation of the proline by chloramine-T, 3) development of chromophore between p-dimethylamino-bezaldehyde in Ehrlich's reagent and hydroxyproline. Although this step is accurate and sensitive, the hydrolysis by $\mathrm{HCl}$ followed by drying may be not suitable for the automated screening process. To assay the prolyl 4-hydroxylase activity in the immortalized rat hepatic stellate HSC-T6 cells, the cell culture condition needed to be optimized by the treatment with various concentrations of reagents for different times in HSC-T6 cells. First of all, the immortalized rat stellate HSC-T6 cells were incubated for $12 \mathrm{~h}$, $24 \mathrm{~h}$ and $48 \mathrm{~h}$, respectively under normoxia or hypoxia states. As seen in Fig. 1, the content of HYP was highest when incubated in the presence of ascorbate for $24 \mathrm{~h}$ under hypoxia, implying the increased production of collagen in hepatic stellate cells.

It was suggested that cobalt chloride $\left(\mathrm{CoCl}_{2}\right)$ could mimic the $\mathrm{O}_{2}$ sensing role of mitochondria by increasing reactive oxygen species generation during normoxia, both in terms of gene up-regulation and cell death promotion in many cellular systems (Ciafre et al., 2007). Therefore, we examined the effect of $\mathrm{CoCl}_{2}$ on the production of HYP. The treatment with $\mathrm{CoCl}_{2}$ at 5

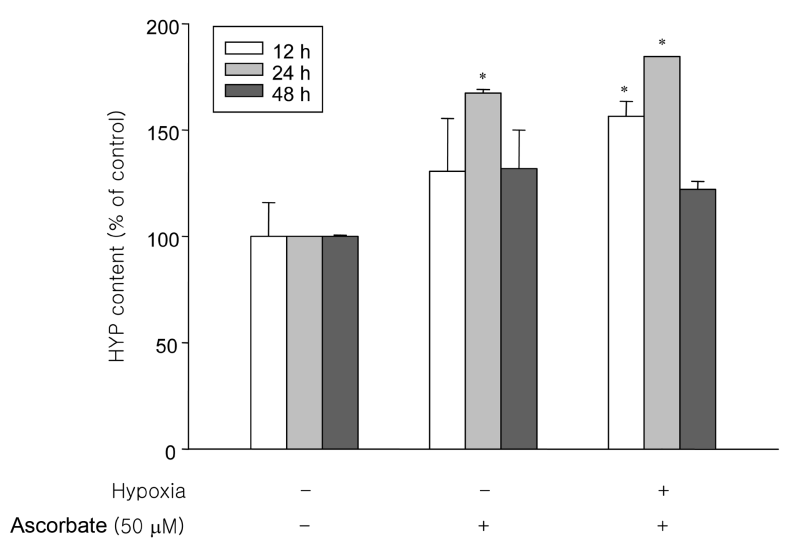

Fig. 1. Effects of ascorbate on the production of 4-hydroxyproline (HYP) in HSC-T6 cells. The HSC-T6 cells were treated with ascorbate under the hypoxia or normoxia. After incubation for $12 \mathrm{~h}, 24 \mathrm{~h}$, or $48 \mathrm{~h}$, cells were harvested and the content of HYP was measured. bars., the mean \pm S.D. $(n=3)$. Asterisk $(*)$ indicates significant difference $(p<0.05)$ compared with the control. $\mu \mathrm{M}$ along with $50 \mu \mathrm{M}$ of ascorbate resulted in the highest production of HYP which was similar to that cultured with ascorbate under hypoxia (Fig. 2A). This result suggests that $\mathrm{CoCl}_{2}$ could be very useful to increase the level of HYP when the anaerobic chamber is not available. Lactate has previously been demonstrated as a possible alternative to hypoxia (Constant et al., 2000). Therefore, we treated the lactate to the media under hypoxia or normoxia to see whether the lactate would have any effects on the level of HYP. As seen in Fig. 2B, the treatment with the lactate $(5 \mathrm{mM})$ did not increase the level of HYP as much as the ascorbate treatment did under hypoxia. Overall, it is suggested that the ascorbate $(50 \mu \mathrm{M})$ in a hypoxic condition for $24 \mathrm{~h}$ resulted in the maximal increase of HYP 1.8 fold. Alternatively, treatments with cobalt chloride $(5 \mu \mathrm{M})$ and ascorbate $(50 \mu \mathrm{M})$ in normoxic states exhibited similar effect on the production of HYP.

(A)

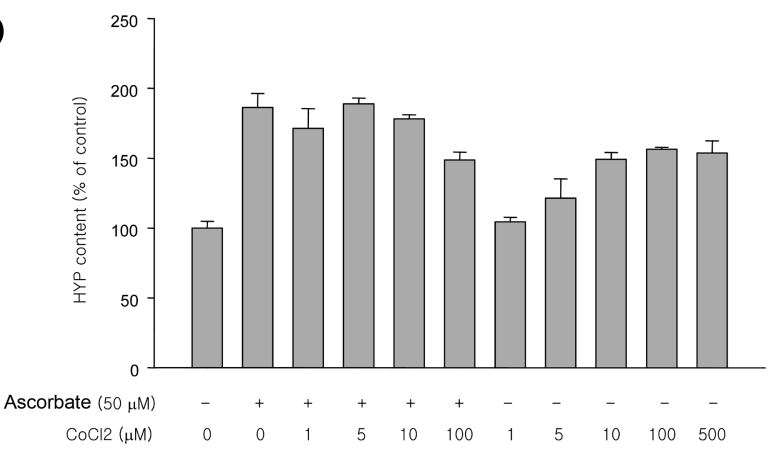

(B)

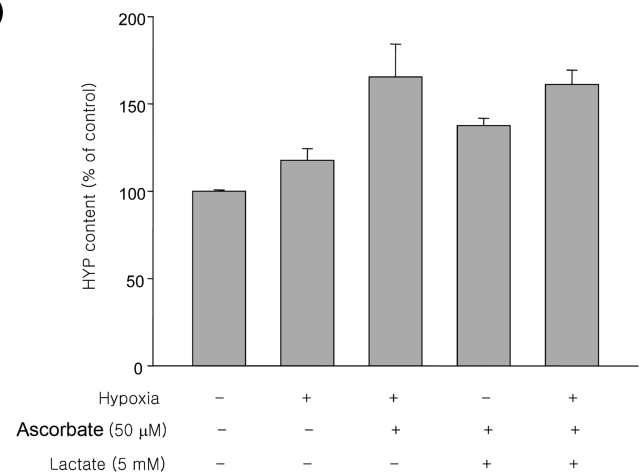

Fig. 2. The ascorbate and lactate increased the production of HYP. (A) The HSC-T6 cells were treated with ascorbate and/or cobalt chloride under the hypoxia or normoxia. After incubation for $24 \mathrm{~h}$, cells were harvested and the content of HYP was measured as described in the Materials and Methods. (B) The HSC-T6 cells were treated with ascorbate and lactate under the hypoxia or normoxia. After incubation for $24 \mathrm{~h}$, cells were harvested and the content of HYP was measured. bars., the mean \pm S.D. $(\mathrm{n}=3)$. 
In our experimental condition, a known prolyl hydroxylase inhibitor, HOE 077 (pyridine-2, 4-dicarboxylic acid bis-[(2methoxy-ethyl)-amide]) and its derivatives, pyridine-2, 4-dicarboxylic acid diethyl ester and, pyridine-2, 4-dicarboxylic acid (a prodrug of HOE 077) at $10 \mu \mathrm{M}$ inhibited the enzyme activity by $15.5 \%, 10.8 \%$, and $19.7 \%$, respectively (Fig. 3). These results coincided with previous reports from liver tissues (Matsumura et al., 1997). In previous report, PPAR- $\gamma$ agonists decreased the synthesis of collagen (Miyahara et al., 2000). In this study, $10 \mu \mathrm{M}$ rosiglitazone, one of the PPAR- $\gamma$ agonist, also decreased the collagen prolyl hydroxylase activity by $32.3 \%$ compared to control.

Since stellate cells are the key fibrogenic cells, we examine the effect of hypoxia on the smooth muscle $\alpha$-actin, a marker of activated stellate cells. The level of the smooth muscle $\alpha$-actin was significantly increased under hypoxia (Fig. 4), suggesting that our experimental condition could work for screening the anti-fibrotic compounds. The treatment with rosiglitazone decreased the protein level of the smooth muscle $\alpha$-actin.

Liver fibrosis arises from the overproduction of extracellular matrix containing collagen due to hepatocyte necrosis resulting from chronic inflammation precipitated by viruses, alcohol, and other causes. As the liver becomes fibrotic, there are both quantitative and qualitative changes in composition of the hepatic

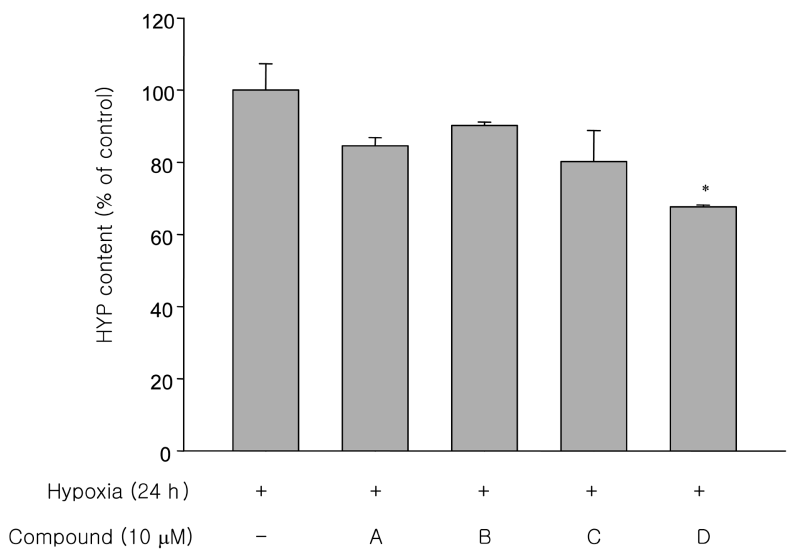

Fig. 3. Rosiglitazone and HOE 077 inhibited the production of HYP. The HSC-T6 cells were treated with A) HOE 077 (pyridine-2, 4-dicarboxylic acid bis-[(2-methoxy-ethyl)-amide]), B) its derivatives, pyridine-2, 4-dicarboxylic acid diethyl ester, C) pyridine-2, 4-dicarboxylic acid (a prodrug of HOE 077), and D) rosiglitazone at $10 \mu \mathrm{M}$, respectively. After incubation for 24 $\mathrm{h}$ under hypoxia, cells were harvested and the content of HYP was measured. bars., the mean \pm S.D. $(n=3)$. Asterisk $(*)$ indicates significant difference $(p<0.05)$ compared with the control.

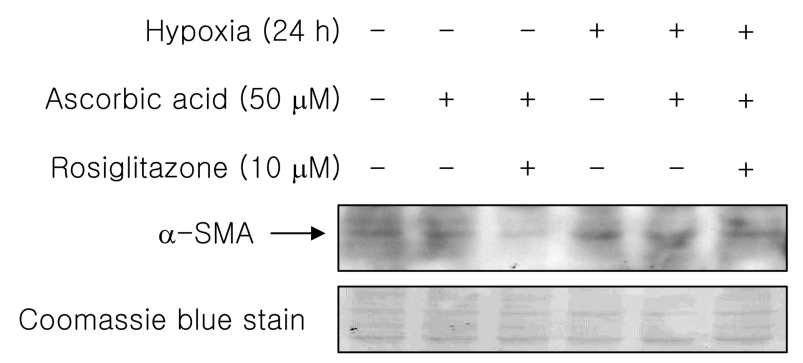

Fig. 4. Immunoblot analysis of smooth muscle $\alpha$-actin $(\alpha$ SMA). The HSC-T6 cells were cultured under the hypoxia or normoxia. After incubation for $24 \mathrm{~h}$, cells were harvested and $25 \mu \mathrm{g}$ of cytosolic protein was subjected to a $10 \%$ SDS-PAGE and then transferred to a PVDF membrane as described in the Materials and Methods. An antibody against rabbit anti- $\alpha$ SMA was used to examine the protein level of $\alpha$-SMA. These data are representative of three independent experiments.

extracellular matrix (ECM). The total content of collagens and noncollagenous components increases 3-5 fold, accompanied by the shift in the type of ECM in subendothelial space from collagen III, IV and laminin to interstitial type matrix containing collagen I and fibronectin (Kim et al., 1998).

Stellate cells are activated by a paracrine effect through the mediation of some factors from necrotic hepatocytes, from Kupffer cells, or endothelial cells (Initiation). Activation is then maintained by the autocrine and paracrine systems involving TGF- $\beta 1$ and PDGF, resulting in enhanced production of ECM and progressive fibrosis (Perpetuation). Besides these factors, stellate cells are activated by ascorbate, carbon tetrachloride, dimethylnitrosamine, alcohol, or hepatitis virus. Collagen prolyl hydroxylase activity increased in the aortic wall of rabbits exposed to chronic hypoxia (Turto et al., 1979). Prolyl hydroxylase required molecular oxygen, $\alpha$-ketoglutarate, ferrous iron and ascorbate for its activity. Ascorbate is required for the hydroxylation of collagen (Levene and Bates, 1976), by maintaining the iron in the active Fe(II) form.

Treatment of chronic hepaptitis with antiviral agents such as interferon and preventive therapy for hepatocellular necrosis have been tried so far, but no direct therapy has been established which inhibits fibrosis. The assay procedure described here took only 3 days after treatment with agents, while assays from the primary stellate cells or liver tissues have taken as long as several weeks. Considering the time and expenses, this assay method could be useful to screen the inhibitors of prolyl 4-hydroxylase to treat the fibrosis. However, relatively large volumes of reagents and the hydrolyzing step of the protein by $\mathrm{HCl}$ followed by drying could make this assay method difficult 
for massive screening. The development of an antibody specific to HYP may overcome the limitations.

\section{ACKNOWLEDGEMENTS}

This paper was supported in part by research funds of Chonbuk National University. Authors thank Professor Eung-Seok Lee (Yeungnam University) for providing HOE 077, pyridine2, 4-dicarboxylic acid diethyl ester and, pyridine-2, 4-dicarboxylic acid.

\section{REFERENCES}

Bickel, M., Baringhaus, K. H., Gerl, M., Gunzler, V., Kanta, J., Schmidts, L., Stapf, M., Tschank, G., Weidmann, K., and Werner, U. (1998). Selective inhibition of hepatic collagen accumulation in experimental liver fibrosis in rats by a new prolyl 4-hydroxylase inhibitor. Hepatology 28, 404-411.

Ciafre, S. A., Niola, F., Giorda, E., Farace, M. G., and Caporossi, D. (2007). $\mathrm{CoCl}(2)$-simulated hypoxia in skeletal muscle cell lines: Role of free radicals in gene up-regulation and induction of apoptosis. Free Radic. Res. 41, 391-401.

Constant, J. S., Feng, J. J., Zabel, D. D., Yuan, H., Suh, D. Y., Scheuenstuhl, H., Hunt, T. K., and Hussain, M. Z. (2000). Lactate elicits vascular endothelial growth factor from macrophages: a possible alternative to hypoxia. Wound Repair Regen. 8, 353360.

Hirsila, M., Koivunen, P., Gunzler, V., Kivirikko, K. I., and Myllyharju, J. (2003). Characterization of the human prolyl 4-hydroxylases that modify the hypoxia-inducible factor. J. Biol. Chem. 278, 30772-30780.

Jamall, I. S., Finelli, V. N., and Que Hee, S. S. (1981). A simple method to determine nanogram levels of 4-hydroxyproline in biological tissues. Anal. Biochem. 112, 70-75.

Kim, Y., Ratziu, V., Choi, S. G., Lalazar, A., Theiss, G., Dang, Q.,
Kim, S. J., and Friedman, S. L. (1998). Transcriptional activation of transforming growth factor betal and its receptors by the Kruppel-like factor $\mathrm{Zf9} /$ core promoter-binding protein and Sp1. Potential mechanisms for autocrine fibrogenesis in response to injury. J. Biol. Chem. 273, 33750-33758.

Kolar, K. (1990). Colorimetric determination of hydroxyproline as measure of collagen content in meat and meat products: NMKL collaborative study. J. Assoc. Off. Anal. Chem. 73, 54-57.

Langrock, T., Garcia-Villar, N., and Hoffmann, R. (2007). Analysis of hydroxyproline isomers and hydroxylysine by reversedphase HPLC and mass spectrometry. J. Chromatogr. B. Analyt. Technol. Biomed. Life Sci. 847, 282-288.

Levene, C. I., and Bates, C. J. (1976). The effect of hypoxia on collagen synthesis in cultured 3T6 fibroblasts and its relationship to the mode of action of ascorbate. Biochim. Biophys. Acta 444, 446-452.

Matsumura, Y., Sakaida, I., Uchida, K., Kimura, T., Ishihara, T., and Okita, K. (1997). Prolyl 4-hydroxylase inhibitor (HOE 077) inhibits pig serum-induced rat liver fibrosis by preventing stellate cell activation. J. Hepatol. 27, 185-192.

Miyahara, T., Schrum, L., Rippe, R., Xiong, S., Yee, H. F., Jr., Motomura, K., Anania, F. A., Willson, T. M., and Tsukamoto, H. (2000). Peroxisome proliferator-activated receptors and hepatic stellate cell activation. J. Biol. Chem. 275, 35715-35722.

Ono, M., Yoshida, A., Ito, Y., and Nohara, T. (1999). Phenethyl alcohol glycosides and isopentenol glycoside from fruit of Bupleurum falcatum. Phytochemistry 51, 819-823.

Tredget, E. E., Falk, N., Scott, P. G., Hogg, A. M., and Burke, J. F. (1990). Determination of 4-hydroxyproline in collagen by gas chromatography/mass spectrometry. Anal. Biochem. 190, 259-265.

Turto, H., Lindy, S., Uitto, J., Helin, P., Garbarsch, C., and Lorenzen, I. B. (1979). Increased collagen prolyl hydroxylase activity in the aortic wall of rabbits exposed to chronic hypoxia. Atherosclerosis 33, 379-384.

Vogel, S., Piantedosi, R., Frank, J., Lalazar, A., Rockey, D. C., Friedman, S. L., and Blaner, W. S. (2000). An immortalized rat liver stellate cell line (HSC-T6): a new cell model for the study of retinoid metabolism in vitro. J. Lipid Res. 41, 882-893. 